\title{
Preparation, characterization, and evaluation of some ashless detergent/dispersant additives for lubricating engine oil
}

\author{
Nehal S. Ahmed ${ }^{1} \cdot$ Amal M. Nassar $^{1} \cdot$ Hamdy S. Abdel-Hameed ${ }^{1} \cdot$ Ahmed F. El-Kafrawy $^{2}$
}

Received: 20 November 2014/ Accepted: 12 May 2015/Published online: 31 May 2015

(c) The Author(s) 2015. This article is published with open access at Springerlink.com

\begin{abstract}
In the present work, different ashless detergent/ dispersant additives were prepared via reaction of different primary amines with propylene oxide, and the products which obtained were reacted with different organic acids. The structures of the prepared compounds were confirmed using fourier transform infrared spectroscopy (FT-IR), Proton nuclear magnetic resonance (1HNMR), and gel permeation chromatography (GPC) for determination of molecular weight. All the prepared compounds were found to be soluble in lubricating oil. The efficiency of the prepared compounds as antioxidants and detergent/dispersant additives for lubricating oil was investigated. It was found that the additives have excellent power of dispersion, detergency, and the most efficient additives as antioxidant those prepared by using di- $n$-butyldithio phosphoric acid.
\end{abstract}

Keywords Lubricating oil additives - Ashless detergents and dispersants · Antioxidants · Propylene oxide

\section{Introduction}

Lubricating oils play a crucial role in both domestic and industrial processes. Proper applications of lubricants increase the lifetime and efficiency of machinery and

Nehal S. Ahmed

mynehal@yahoo.com

1 Department of Petroleum Applications, Egyptian Petroleum Research Institute, Nasr City, Cairo, Egypt

2 Chemistry Department, Faculty of Science, Ain Shams University, Abbasiya, Cairo, Egypt decrease long-term costs in terms of energy consumption, maintenance requirements and reduce operating temperatures [1-3].

The primary function of a lubricant is to create a film barrier between moving mechanical parts to reduce friction and wear. It also acts as a coolant, suppresses harmful deposit formation, and controls corrosion/ oxidation. Since the base oil alone would struggle to meet these challenging demands, performance-enhancing additives in tailor-made formulations are added to the lubricant formulation $[4,5]$.

In the 1950s, a new type of additive, a non-metallic or "ashless" dispersant, was introduced to help keep engines clean. This product, known as a succinimide dispersant, was a relatively high molecular weight polyisobutenyl group attached to a polar end group [6].

Organic species in mineral oils and lubricants are subject to deterioration by oxidation, especially at high temperatures and in the presence of air or metal. Such deterioration often leads to buildup of insoluble deposits or sludge and viscosity increase during use. In order to avoid the problems, lubricants need to possess superior oxidation stability [7].

Detergents and dispersants, often called DD or HD (heavy-duty) additives have been indispensable for the development of modern engine oils for gasoline and diesel combustion motors. These lubricants are especially exposed to severe stress due to the high temperatures and the additional influence of aggressive blow by gases of the combustion process $[8,9]$.

The original definition of detergents refers to their cleaning properties similar to the detergents in washing agents although their function appears to be more of dispersing particulate matters such as abrasive wear and soot particles rather than cleaning up existing dirt [10].

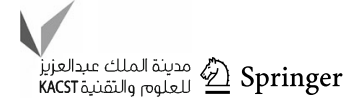


The key function of a dispersant in an industrial or automotive lubricant formulation is to reduce oil thickening caused by accumulation and agglomeration of soot particles.

In the present work, two propoxylated amines were prepared via reaction of propylene oxide with (triethylenetetramine and tetraethylenepentamine). Then different compounds were synthesized via reaction of prepared propoxylated amines with three different organic acids, (stearic acid, dodecylbenzenesulphonic acid, and di$n$-butyldithio phosphoric acid), where these compounds suggested as detergent/dispersants additives due to presence of amino groups and as antioxidants due to presence of Di-n-butyldithio phosphoric acid which has antioxidant properties Table 1.

\section{Experimental}

\section{Synthesis of propoxylated amines}

One mole of propylene oxide (PO) and one mole of primary amines (Triethylenetetramine and Tetraethylenepentamine) were mixed in three-round bottom flask equipped with a mechanical stirrer, reflux condenser, and thermometer. The reaction mixture was maintained at temperature $120 \pm 5{ }^{\circ} \mathrm{C}$ with continuous stirring for about $4 \mathrm{~h}$, and then cooled to the ambient temperature. The products were obtained (A and B) and their designation is shown in Table 2.

Table 1 Purity of chemicals used

\begin{tabular}{lll}
\hline Compounds & Purity $(\%)$ & Company \\
\hline Propylene oxide & 99.00 & Merck Company \\
Triethylenetetramine & 97.00 & Aldrich Company \\
Tetraethylenepentamine & 30.00 & Aldrich Company \\
Stearic acid & 98.50 & Aldrich Company \\
Dodecylbenzenesulphonic acid & 95.00 & Aldrich Company \\
\hline
\end{tabular}

Table 2 The designation of prepared compounds

\begin{tabular}{ll}
\hline Abbreviation & Prepared compounds \\
\hline A & Triethylenetetramine+PO \\
$\mathrm{A}_{1}$ & $\mathrm{~A}+$ Stearic acid \\
$\mathrm{A}_{2}$ & $\mathrm{~A}+$ Dodecylbenzenesulphonic acid \\
$\mathrm{A}_{3}$ & $\mathrm{~A}+$ Di-n-butyldithiophosphoric acid \\
$\mathrm{B}$ & Tetraethylenepentamine + PO \\
$\mathrm{B}_{1}$ & $\mathrm{~B}+$ Stearic acid \\
$\mathrm{B}_{2}$ & $\mathrm{~B}+$ Dodecylbenzenesulphonic acid \\
$\mathrm{B}_{3}$ & $\mathrm{~B}+$ Di-n-butyldithiophosphoric acid \\
\hline
\end{tabular}

\section{Reaction of propoxylated amines with different organic acids}

The reaction was carried out in three-round bottom flask equipped with a mechanical stirrer, efficient condenser, and thermometer. In the flask was placed one mole of the prepared propoxylated amines and one mole of different organic acids (stearic acid, dodecylbenzensulphonic acid, and di- $n$-butyldithiophosphoric acid). The reactants were mixed with an equal weight of xylene and heated gradually to $150 \pm 5{ }^{\circ} \mathrm{C}$ with continuous stirring for about $4 \mathrm{~h}$ using a well-controlled thermostat. The extent of reaction was followed by monitoring the amount of liberated water to give products; therefore, we have six different products, their designation shown in Table 2.

\section{Characterization of the prepared compounds}

\section{Infrared spectroscopic analysis}

The prepared compounds were characterized by using FTIR. Spectrometer Model Type "Nicolet iS10 FT-IR Spectrometer," made in USA.

Spectral resolution: better than $0.4 \mathrm{~cm}^{-1}$, non-apodized, and sample prepared as disk.

Room temperature, $\mathrm{KBr}$ optics, DTGS detector, $4 \mathrm{~cm}^{-1}$ spectral resolutions.

Maximum speed: 40 spectra per second at $16 \mathrm{~cm}^{-1}$ resolution.

\section{Determination of molecular weights}

The molecular weights of the prepared compounds were determined using Agilent (Gel Permeation Chromatography) GPC water model 600E.

\section{Proton magnetic resonance analysis}

The prepared compounds were characterized by $1 \mathrm{H}$ NMR spectroscopy. Using 1H NMR type (300 M.Hs. spectrophotometer W-P-300, Bruker).

\section{Solubility Test}

The solubility of the prepared compounds was investigated by dissolving the compounds in free additive base oil (SAE 30) from "Cooperation Company for petroleum." In a conical flask, $2 \mathrm{~g}$ of compounds was added to previously weighted base oil (100 g) and the mixture was allowed to stand overnight. The conical flask was immersed in an oil bath placed on a thermostated hot plate fixed over a magnetic stirrer. The temperature of the oil bath was then raised 
to $60{ }^{\circ} \mathrm{C}$ and at this point the mixture was agitated by a Teflon covered magnet for $20 \mathrm{~min}$.

\section{Evaluation of the prepared compounds as Lube Oil additives}

\section{As antioxidants}

The lube oil samples as well as its blends with $2 \%$ by weight of each of the prepared additives were subjected to severe oxidation condition in the presence of copper and iron strips at $165.5^{\circ} \mathrm{C}$ for $72 \mathrm{~h}$ using the Indiana test method of oxidation [12]. The oxidation stability of the lube oil blends were determined by taking samples at $24 \mathrm{~h}$ intervals to $72 \mathrm{~h}$. These samples were tested for:

Variation of viscosity ratio $V / V_{o}$ The variation of viscosity ratio $\left(V / V_{\mathrm{o}}\right)$ has been determined using IP 48/86 method, where: $V=$ kinematic viscosity at $40{ }^{\circ} \mathrm{C}$ of sample after oxidation.

$V_{\mathrm{o}}=$ kinematic viscosity at $40{ }^{\circ} \mathrm{C}$ of sample before oxidation.

The prepared compounds were evaluated using Koehler laboratory bath Model K2337800000, made in USA.

Change in total acid number ( $\triangle T A N)$ The change has been calculated according to IP 177/83 method, where

$\Delta \mathrm{TAN}=($ total acid number of sample after oxidation - total acid number of sample before oxidation).

The prepared compounds were evaluated using Potentiometric Titration Workstation (Mono burette), "TitraLab 960," made in France.

Optical density using infrared techniques The infrared spectra of oxidized oils have been determined in the range of the carbonyl group absorbance $\left(1500-1900 \mathrm{~cm}^{-1}\right)$. The spectra have been superimposed upon that of unoxidized oil. The absorbance (A) has been calculated according to

$A=\log I / I o$,

where $I$ is $\%$ transmittance of the oil after oxidation and Io is the transmittance of the oil before oxidation.

\section{As Detergents/Dispersants}

Spot method [11, 12] Drops were taken from the samples being oxidized in the Indiana test after $24 \mathrm{~h}$ intervals of oxidation and up to $72 \mathrm{~h}$ to make spots on special filter paper (Durieux 122) and the dispersancy of the samples were measured as follows:
$\%$ dispersancy $=\frac{\text { Diameter of the black spot }}{\text { Diameter of the total spot }} \times 100$.

The efficiency of dispersants has been classified as follows:

- Up to $30 \%$ : no dispersancy.

- 30-50\%: medium dispersancy.

- 50-60\%: good dispersancy.

- 60-70\%: very good dispersancy.

- Above $70 \%$ : excellent dispersancy.

Determination of sludge [13] The essential feature of the method for determining the content of existent sludge is a $1 \mathrm{~h}$ centrifuging operation in $\left(4233_{\mathrm{ECT}}\right.$ laboratory centrifuge) at $3000 \mathrm{rpm}$, with $10 \mathrm{~g}$ of the test oil in the centrifuge tubes. After centrifuging, the clarified oil is decanted off, then $10 \mathrm{ml}$ of isooctane is added as wash liquid to the tube containing the sludge in the form of a cake, and the sample is again centrifuged for $15 \mathrm{~min}$. The operation is repeated until the sludge is washed completely free of oil. The washed sludge, together with the centrifuge tube, is brought to weight in a thermostat at $105{ }^{\circ} \mathrm{C}$ and the amount of sludge is determined by weighing and expressed as a percentage of the original oil sample.

$\%$ Sludge $=\frac{\text { Weight of sample after centrifuge }}{\text { Weight of sample }} \times 100$.

\section{Determination of the potential detergent dispersant efficiency (PDDE) [14]}

The detergent/dispersant efficiency of the additives was measured by two methods: washing efficiency and detergent index. The washing efficiency is measured by thin layer chromatography method. It aims to evaluate how effective the additives are in removing the impurities from the surface. The different additives bring the carbon black in different heights on the paper based on the washing efficiency of the additive. The washing efficiency is measured in millimeters between the point where the suspension was put and the height where the oil brings the suspension with the heptane. The detergent index characterizes the dispersion stabilizing efficiency of the additive, thus how they keep the impurities in a dispersed phase. The test is based on centrifugation.

The results of numerous experiments attested that these two methods were suitable to estimate the percentage of potential detergent dispersant efficiency (PDDE, \%) in oil solutions

$\mathrm{PDDE}=\frac{\mathrm{DI}+\mathrm{WE}}{225} \times 100$, 
Scheme 1 Reaction of triethylenetetramine with propylene oxide<smiles>NCCNCCNCCN</smiles>

Triethylenetetramine

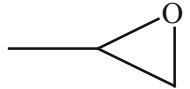

Propylene oxide $120^{\circ} \mathrm{C} / 4$-hrs.<smiles>CCCCCCC(C)O</smiles>

Scheme 2 Reaction of tetraethylenepentamine with propylene oxide<smiles>NCCNCCNCCNCCN</smiles>

Tetraethylenepentamine

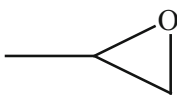

Propylene oxide<smiles>CC(O)CNCCNCCNCCNCCN</smiles>

Product B

where DI is the detergent index (\%), WE is the washing efficiency $(\mathrm{mm}), 225$ is the maximum value of $\mathrm{DI}+\mathrm{WE}$ $\left(\mathrm{DI}_{\max }=100, \mathrm{WE}_{\max }=125\right)$.

\section{Results and discussion}

\section{Synthesis of propoxylated amines}

Preparation of propoxylated amines is illustrated in Schemes 1, 2, as follows:

The determined mean molecular weights of the products (A and B) have been found to be very near from that calculated theoretically and is shown in Table 3 .

- The infrared spectrum of product (A) is given in Fig. 1 which illustrates the following: The hydroxyl $(\mathrm{OH})$ bands appear clearly near to $3283 \mathrm{~cm}^{-1}$ as broad bands. The amino (NH) bands appear clearly near to $3260 \mathrm{~cm}^{-1}$. C-H of alkanes appears in the range of 2856 and $2925 \mathrm{~cm}^{-1}$. C-O appears at $1128 \mathrm{~cm}^{-1}$. CH of $\mathrm{CH}_{3}$ group appears at 1455 and $1355 \mathrm{~cm}^{-1}$. $\mathrm{CH}$ of $\mathrm{CH}_{2}$ group appears at 1455 and $1355 \mathrm{~cm}^{-1} . \mathrm{N}-\mathrm{H}$ group appears at $1598 \mathrm{~cm}^{-1}$.

- The $1 \mathrm{H}$ NMR spectrum of product $(\mathrm{A})$ is given in the following Table 4 .

\section{Reaction of propoxylated amines with different organic acids}

Preparation of products $\left(\mathrm{A}_{1}, \mathrm{~A}_{2}\right.$, and $\left.\mathrm{A}_{3}\right)$ is illustrated in Schemes 3, 4, and 5 as follows:
Table 3 The molecular weight of the prepared compounds

\begin{tabular}{lll}
\hline Products & \multicolumn{2}{l}{ Molecular weight } \\
\cline { 2 - 3 } & Theoretically & Determined \\
\hline A & 204 & 206 \\
$A_{1}$ & 470.48 & 474 \\
$A_{2}$ & 512.49 & 515 \\
$A_{3}$ & 428.34 & 431 \\
$B$ & 247.3 & 248 \\
$B_{1}$ & 515.82 & 504 \\
$B_{2}$ & 513.78 & 511 \\
$B_{3}$ & 471.64 & 475 \\
\hline
\end{tabular}

The determined mean molecular weights of the products $\left(A_{1}, A_{2}\right.$, and $\left.A_{3}\right)$ have been found to very near from that calculated theoretically and is shown in Table 3.

- The infrared spectrum of product $\left(\mathrm{A}_{2}\right)$ is given in Fig. 2 which illustrates the following: The hydroxyl $(\mathrm{OH})$ band appears clearly near to $3301 \mathrm{~cm}^{-1}$ as broad bands. The amino (NH) band appears clearly near to $3301 \mathrm{~cm}^{-1}$. C-H of alkanes appears at 2865 and $2920 \mathrm{~cm}^{-1}$. C-H of aromatic ring appears at $3070 \mathrm{~cm}^{-1}$. The bands of 1,4-disubstitution of aromatic ring are in the range of $833 \mathrm{~cm}^{-1} . \mathrm{C}=\mathrm{C}$ of aromatic ring appears at $1601 \mathrm{~cm}^{-1}$. C-O of alcohol appears at $1123 \mathrm{~cm}^{-1}$. C-H of $\mathrm{CH}_{3}$ group appears at $1463 \mathrm{~cm}^{-1}$. $\mathrm{C}-\mathrm{N}$ of tertiary amine appears at $1220 \mathrm{~cm}^{-1}$. N-CH group appears at $2655 \mathrm{~cm}^{-1}$. $\mathrm{S}=\mathrm{O}$ group appears at $1038 \mathrm{~cm}^{-1}$. C-S appears at $676 \mathrm{~cm}^{-1}$.

- The $1 \mathrm{H}$ NMR spectrum of product $\left(\mathrm{A}_{2}\right)$ is given in the following Table 5 . 


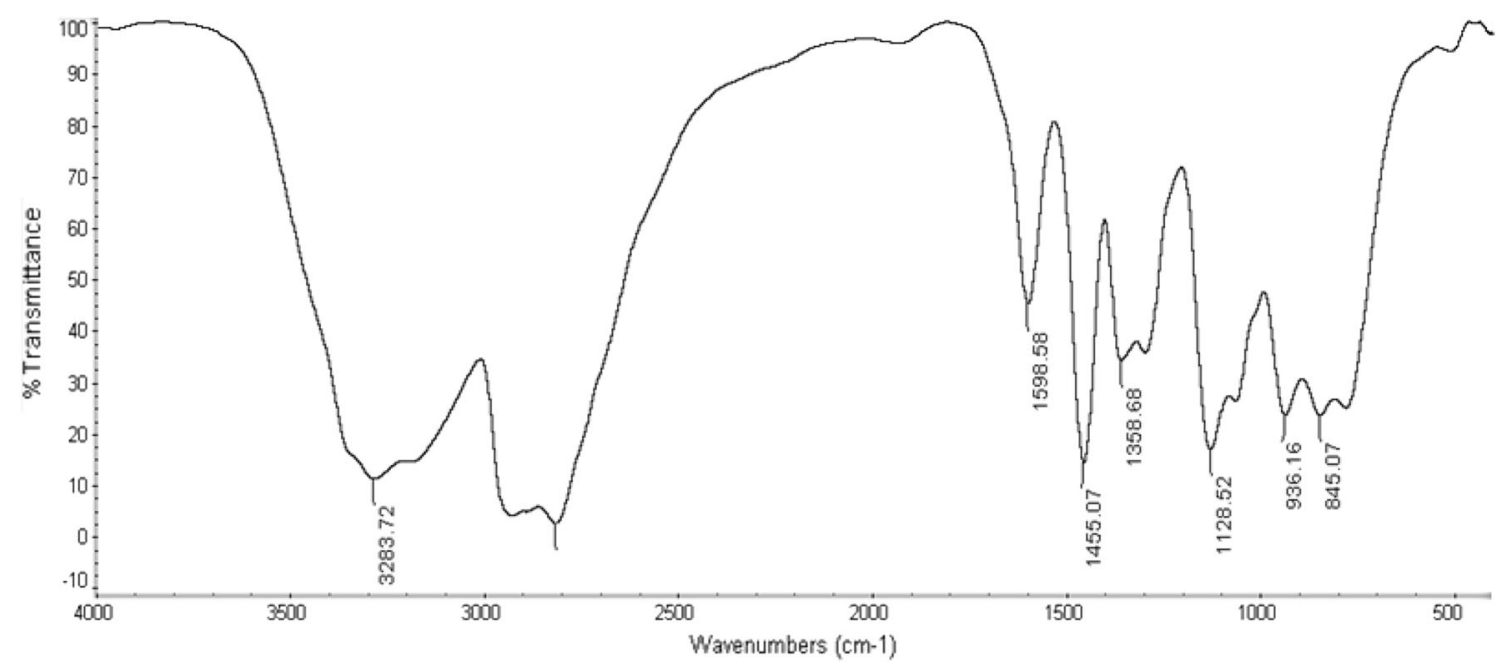

Fig. 1 Infrared spectrum of compound (A)

Table 4 The $1 \mathrm{H}$ NMR spectrum data of product (A)

\begin{tabular}{ll}
\hline Group & Signal appearance $(\mathrm{ppm})$ \\
\hline $\mathrm{OH}$ group & $\delta-3.5$ \\
$\mathrm{NH}$ group & $\delta-2.5$ \\
$\mathrm{CH}_{2}$ attached to $\left(\mathrm{NH}_{2}\right)$ & $\delta-2.7$ \\
$\mathrm{C}-\mathrm{H}$ attached to $\left(\mathrm{OH}\right.$ and $\left.\mathrm{CH}_{3}\right)$ & $\delta-3.3$ \\
$\mathrm{CH}_{3}$ terminal & $\delta-0.96$ \\
\hline
\end{tabular}

\section{Evaluation of the prepared compounds}

\section{As antioxidants}

All the prepared compounds were added to a sample of "SAE-30" lube oil free from any additives, in $2 \%$ concentration, and the blends obtained were subjected to severe oxidation condition as described previously. The change in optical density $\left(\log I / I_{\mathrm{o}}\right)$, total acid number $(\Delta \mathrm{TAN})$, and viscosity ratio $\left(V / V_{\mathrm{o}}\right)$ decreases with increasing the $\mathrm{NH}$ groups in the molecule of amine so the additives prepared from tetraethylenepentamine $\left(\mathrm{B}_{1}-\mathrm{B}_{3}\right)$ are more efficient as antioxidants than that prepared from Triethylenetetramine, the presence of amino group in the structure of the prepared compounds neutralizes some of acidic products of lube oil oxidation [15]. It was found that compound $B_{3}$ is the best as lube oil antioxidants, followed by $\mathrm{B}_{2}$, and then compound $\mathrm{B}_{1}$ comes later. The efficiency of the prepared compound $\mathrm{B}_{3}$ compared with the other is because it contains amino groups and also Di-n-butyldithiophosphoric acid which have antioxidant character.

Effect of used different acids The results of additives of different acid products are given in Figs. 3, 4, 5, 6, 7, and
8. It was found that better oxidation stability is obtained when we use di- $n$-butyldithio phosphoric acid $\left(\mathrm{B}_{3}\right)$, this may be due to the antioxidant character of this acid because it acts as peroxide decomposers so $\mathrm{B}_{3}>\mathrm{A}_{3}$.

As detergents/dispersants

All the prepared compounds have been added to the oil samples in concentration of $2 \mathrm{wt} \%$, using spot test method. Results given in Table 6 show clearly that the prepared compounds have very good and excellent dispersancy power (60-93\%) for sludge and solid particles formed during lube oil oxidation compared with lube oil only $[15,16]$.

It is clear that the addition of these compounds not only disperses solid particles in the oil and thus prevents their agglomeration and precipitation on metallic parts of engines that can cause damage, but also neutralizes some of the acidic products of oxidation due to their basic nature. It is clear from the data that increasing the NH groups in the structures of the prepared compounds, increases their capacity in dispersing sludge and solid particles into lube oil samples used, this may be explained by the fact that the $\mathrm{NH}$ groups form hydrogen bonds with polar groups of oxidation products.

Determination of sludge The prepared additives $\left(\mathrm{A}_{1}-\mathrm{A}_{3}\right)$ and $\left(\mathrm{B}_{1}-\mathrm{B}_{3}\right)$ have been added to lube oil samples in concentration $2 \mathrm{wt} \%$, using the centrifuge test method. The percentages of sludge formation during the oxidation of lube oil sample with and without prepared additives are determined and given in Table 7, which confirms the same results of the antioxidant activity and dispersancy power that compound more efficient as detergent.

Determination the potential detergent dispersant efficiency $(P D D E) \quad$ It was proved also by few differences between 
Scheme 3 Reaction of product (A) with stearic acid

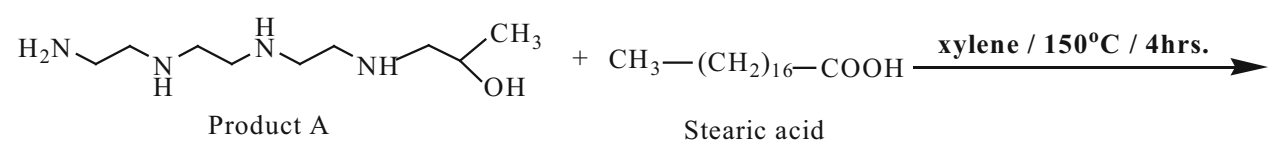<smiles>CCCCCCCCCCCCCCCCCCCCNCC(C)O</smiles>

Product $\mathrm{A}_{1}$
Scheme 4 Reaction of product (A) with dodecylbenzenesulphonic acid

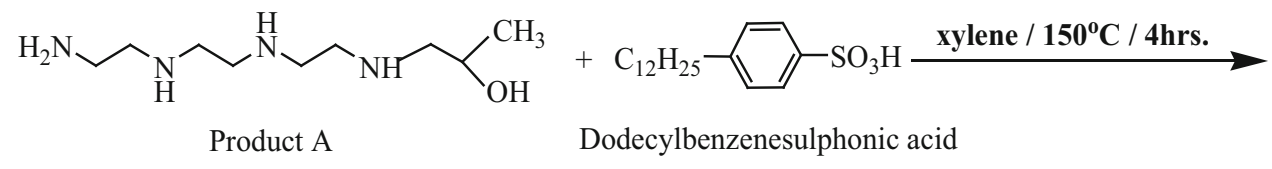<smiles>CCCCCCCCCCCNCCNCCNCCNCC(C)O</smiles>

Product $\mathrm{A}_{2}$
Scheme 5 Reaction of product (A) with di- $n$ butyldithiophosphoric acid

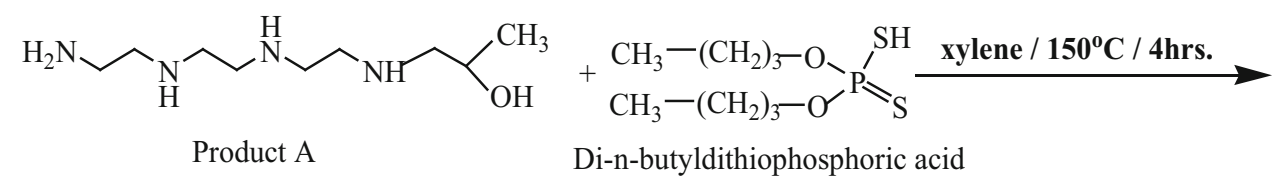

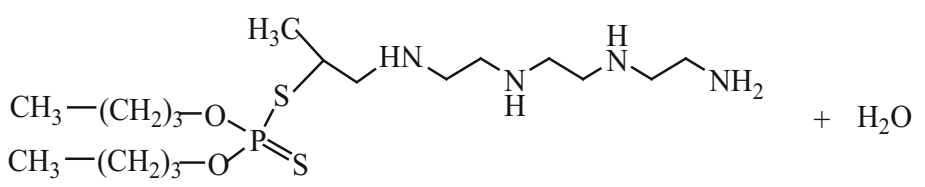
Product $\mathrm{A}_{3}$

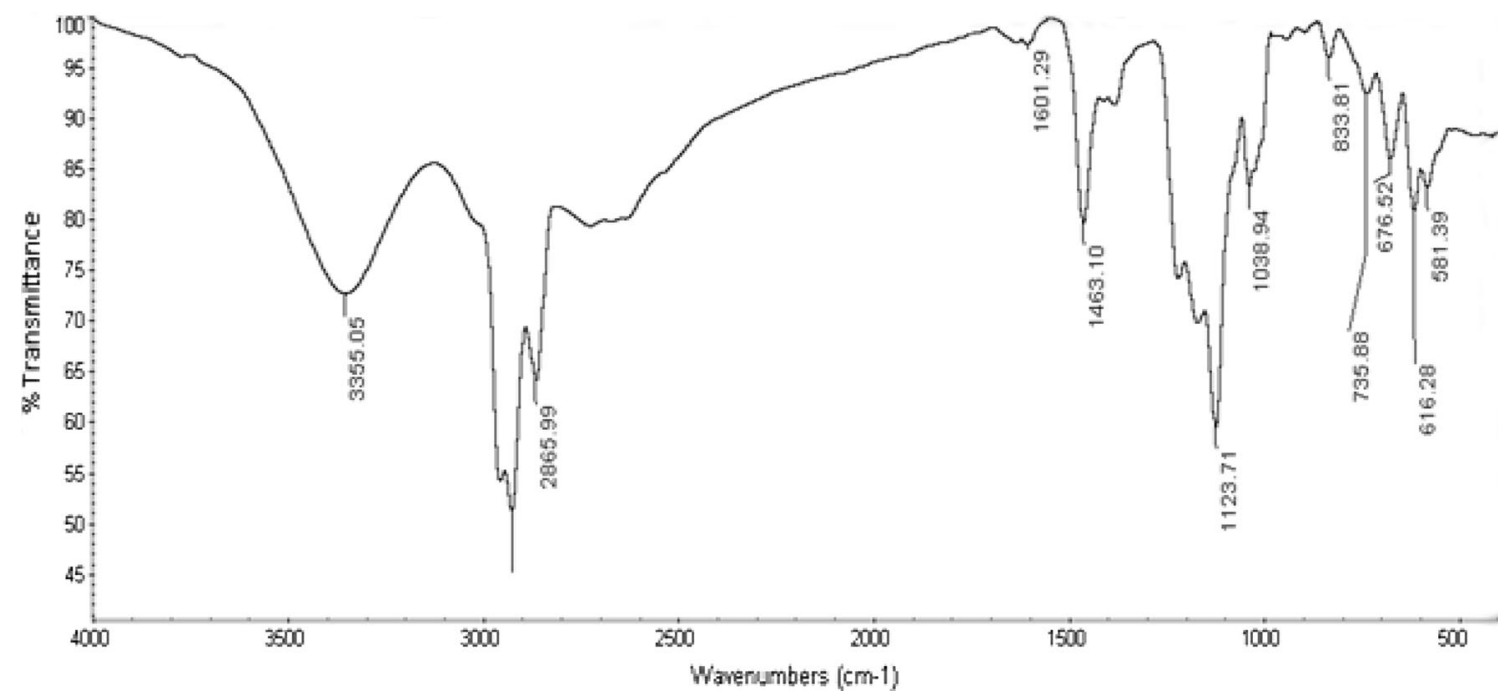

Fig. 2 Infrared spectrum of compound $\left(\mathrm{A}_{2}\right)$ 
Table 5 The $1 \mathrm{H}$ NMR spectrum data of product $\left(\mathrm{A}_{2}\right)$

\begin{tabular}{ll}
\hline Group & Signal appearance $(\mathrm{ppm})$ \\
\hline OH group & $\delta-3.7$ \\
$\mathrm{NH}$ group & $\delta-2.5$ \\
$\mathrm{C}-\mathrm{H}$ & $\delta-7$ and $\delta-7.5$ \\
$\mathrm{C}-\mathrm{H}$ attached to $\left(\mathrm{OH}\right.$ and $\left.\mathrm{CH}_{3}\right)$ & $\delta-3.63$ \\
$\mathrm{CH}_{2}$ attached to benzene ring & $\delta-2.55$ \\
Proton of (-SO2NH-) group & $\delta-8.7$ \\
$\mathrm{CH}_{3}$ terminal & $\delta-0.96$ \\
\hline
\end{tabular}

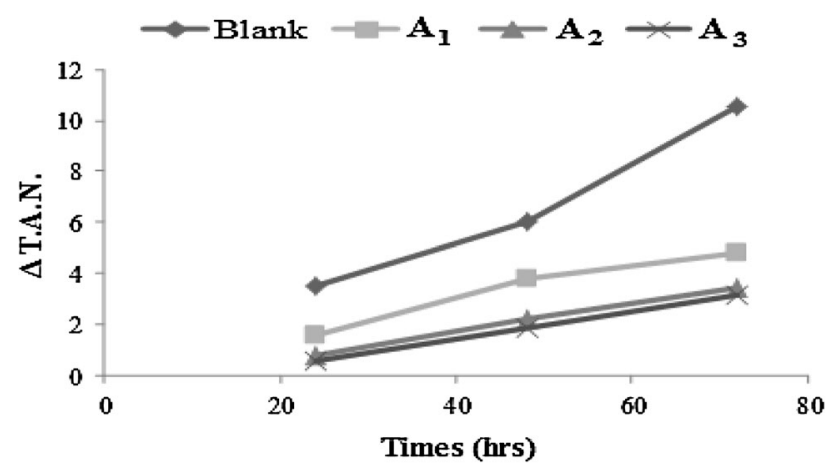

Fig. 3 Variation of $\triangle T$ TAN with oxidation time of lube oil without and with additives $\left(\mathrm{A}_{1}, \mathrm{~A}_{2}\right.$, and $\left.\mathrm{A}_{3}\right)$

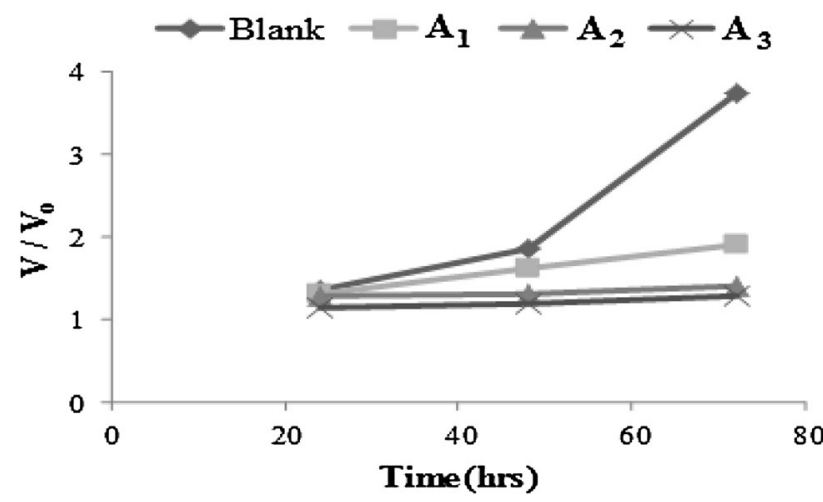

Fig. 4 Variation of $V / V_{\text {o }}$ with oxidation time of lube oil without and with additives $\left(A_{1}, A_{2}\right.$, and $\left.A_{3}\right)$

the potential detergent/dispersant efficiency of the prepared additives $\left(A_{1}-A_{3}\right)$ and $\left(B_{1}-B_{3}\right)$ obtained by centrifugation and paper chromatography tests of their carbon black suspension in Fig. 9. The PDDE values of the prepared additives were high enough above $(80 \%)$ and similar to each other.

It was also confirmed that the polar group $(\mathrm{NH}$ and $\mathrm{OH})$ of the prepared additives has an active role in the mechanism of detergent action.

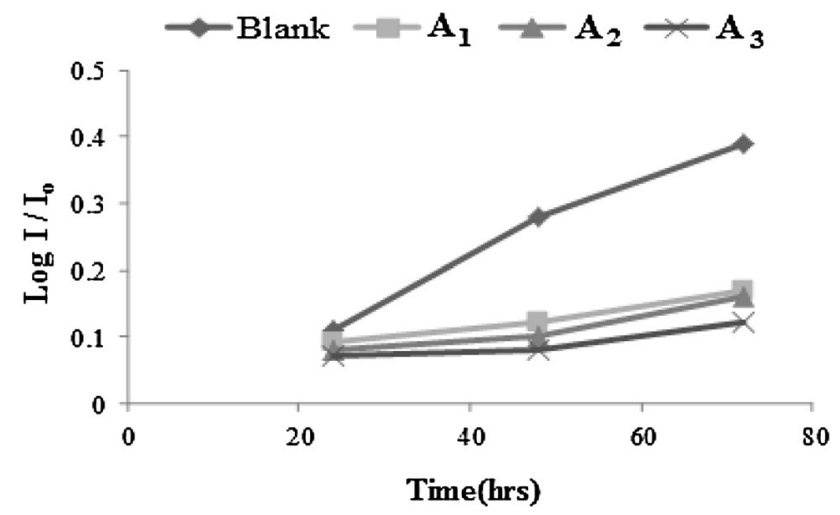

Fig. 5 Variation of $\log I / I_{\mathrm{o}}$ with oxidation time of lube oil without and with additives $\left(\mathrm{A}_{1}, \mathrm{~A}_{2}\right.$, and $\left.\mathrm{A}_{3}\right)$

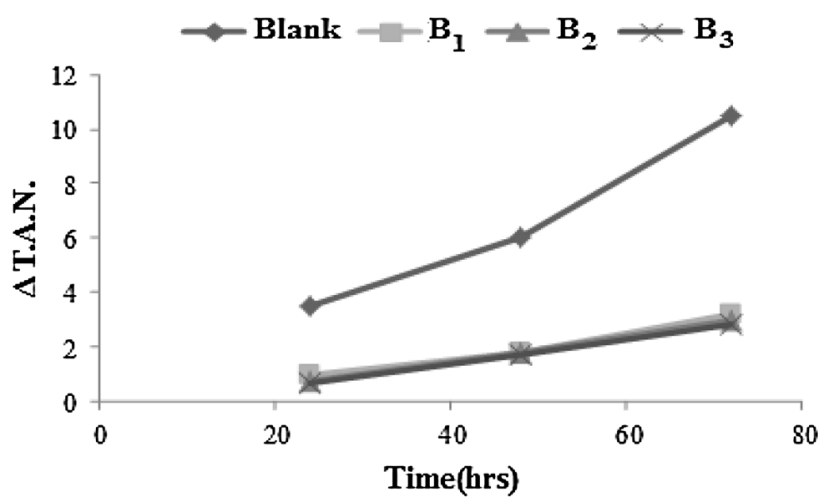

Fig. 6 Variation of $\triangle T$ TAN with oxidation time of lube oil without and with additives $\left(\mathrm{B}_{1}, \mathrm{~B}_{2}\right.$, and $\left.\mathrm{B}_{3}\right)$

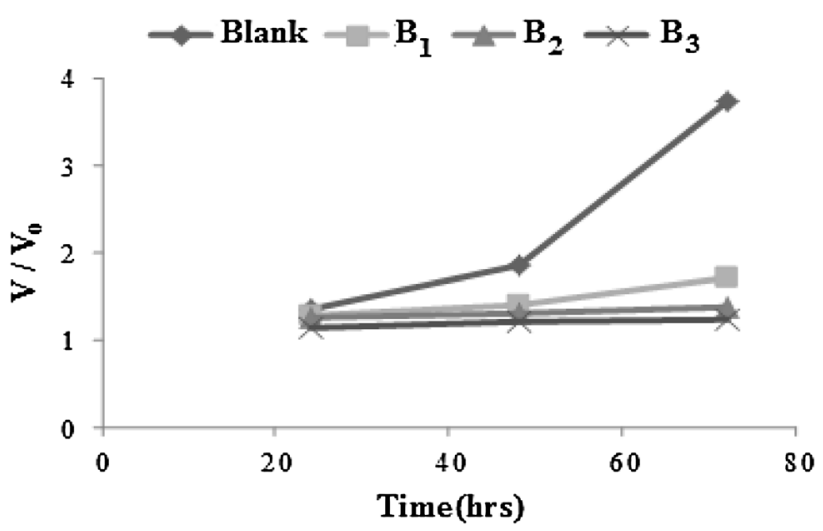

Fig. 7 Variation of $V / V_{\mathrm{o}}$ with oxidation time of lube oil without and with additives $\left(\mathrm{B}_{1}, \mathrm{~B}_{2}\right.$, and $\left.\mathrm{B}_{3}\right)$

Synergism and antagonism of $B_{3}$ with Zinc dialkyldithiophosphate

To a blend of lube oil sample containing $2 \mathrm{wt} \%$ of the prepared additive $\left(\mathrm{B}_{3}\right), 0.5 \mathrm{wt} \%$ of a commercial antioxidant (Zinc dialkyldithio phosphate) has been added to 


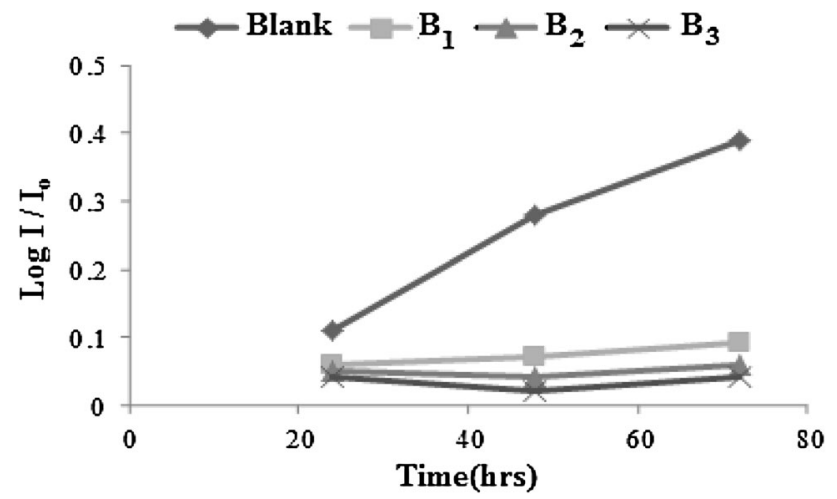

Fig. 8 Variation of $\log I / I_{\mathrm{o}}$ with oxidation time of lube oil without and with additives $\left(\mathrm{B}_{1}, \mathrm{~B}_{2}\right.$, and $\left.\mathrm{B}_{3}\right)$

Table 6 Percentage of dispersion (spot test method) of the lube oil sample and it is blends with additives after different oxidation times (h)

\begin{tabular}{llll}
\hline Sample & \multicolumn{3}{l}{ Percentage of dispersion time $(\mathrm{h})$} \\
\cline { 2 - 4 } & 24 & 48 & 72 \\
\hline Blank & 35 & 33 & 32 \\
$\mathrm{~A}_{1}$ & 80 & 81 & 93 \\
$\mathrm{~A}_{2}$ & 93 & 92 & 67 \\
$\mathrm{~A}_{3}$ & 60 & 64 & 83 \\
$\mathrm{~B}_{1}$ & 85 & 89 & 92 \\
$\mathrm{~B}_{2}$ & 84 & 91 & 91 \\
$\mathrm{~B}_{3}$ & 82 & 88 & 91 \\
\hline
\end{tabular}

Table 7 Percentage of sludge formation after and before addition of prepared additives $\left(\mathrm{A}_{1}-\mathrm{A}_{3}\right)$ and $\left(\mathrm{B}_{1}-\mathrm{B}_{3}\right)$ at oxidation time $(72 \mathrm{~h})$

\begin{tabular}{ll}
\hline Sample & \% of sludge Time $(72 \mathrm{~h})$ \\
\hline $\mathrm{A}_{1}$ & 1.7014 \\
$\mathrm{~A}_{2}$ & 0.9132 \\
$\mathrm{~A}_{3}$ & 0.4522 \\
$\mathrm{~B}_{1}$ & 0.7207 \\
$\mathrm{~B}_{2}$ & 0.4331 \\
$\mathrm{~B}_{3}$ & 0.3843 \\
Blank & 6.6776 \\
\hline
\end{tabular}

prepare additive $\left(\mathrm{B}_{31}\right)$ in order to study the effect of the prepared additive on the oxidation stability of lube oil sample in presence of other type of lube oil additives; results are given Figs. 10, 11, and 12. It was found that the prepared additive $\mathrm{B}_{3}$ has synergistic effect with zinc dialkyldithiophosphate and increases its efficiency as an antioxidant.

Using spot method The prepared additive $\mathrm{B}_{31}$ has been added to lube oil sample in concentration of $2 \mathrm{wt} \%$ by using the spot test method. The results are given in Table 8 ,

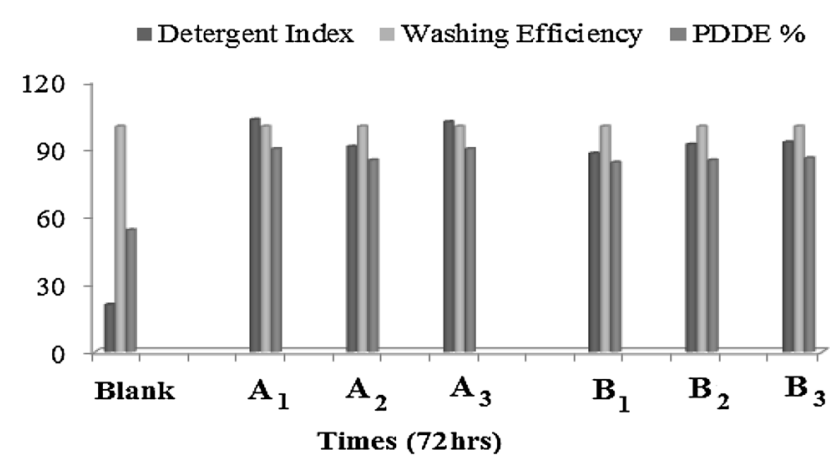

Fig. 9 Detergent index (DI), washing efficiency (WE), and the percentage of potential detergent dispersant efficiency (PDDE) of the prepared additives $\left(\mathrm{A}_{1}-\mathrm{A}_{3}\right)$ and $\left(\mathrm{B}_{1}-\mathrm{B}_{3}\right)$

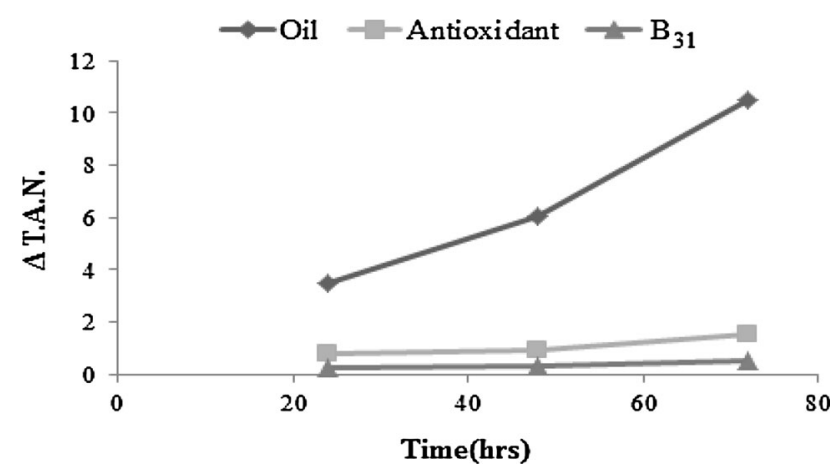

Fig. 10 Variation of $\triangle T A N$ with oxidation time of lube oil without and with $2 \mathrm{wt} \%$ of the prepared additive and $0.5 \mathrm{wt} \%$ of antioxidant $\left(\mathrm{B}_{31}\right)$ after different oxidation hours

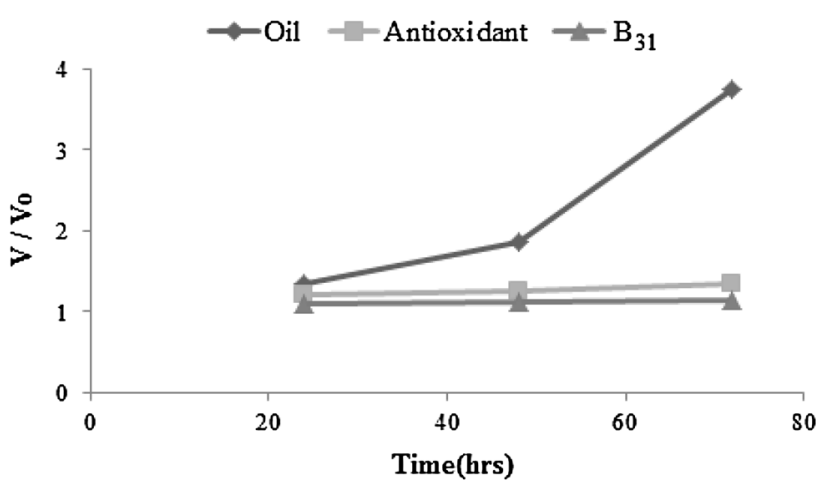

Fig. 11 Variation of $V / V_{\mathrm{o}}$ with oxidation time of lube oil without and with $2 \mathrm{wt} \%$ of the prepared additive and $0.5 \mathrm{wt} \%$ of antioxidant $\left(\mathrm{B}_{31}\right)$ after different oxidation hours

showing clearly that the prepared additive has excellent dispersancy power for the sludge and soil particles formed during lube oil oxidation compared with the lube oil with zinc dialkyldithiophosphate.

Determination of sludge The percentage of sludge formation during the oxidation of lube oil sample with and without additive is determined and the data are given in 


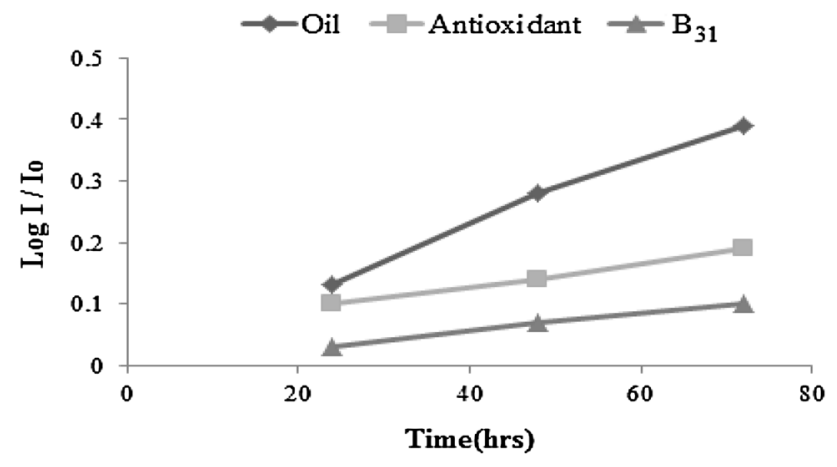

Fig. 12 Variation of $\log I / I_{\mathrm{o}}$ with oxidation time of lube oil without and with $2 \mathrm{wt} \%$ of the prepared additive and $0.5 \mathrm{wt} \%$ of antioxidant $\left(\mathrm{B}_{31}\right)$ after different oxidation hours

Table 8 Percentage of dispersion (spot test method) of the lube oil without and with $2 \mathrm{wt} \%$ of the prepared additive and $0.5 \mathrm{wt} \%$ of antioxidant $\left(\mathrm{B}_{31}\right)$ after different oxidation hours

\begin{tabular}{llcc}
\hline Sample & \multicolumn{3}{l}{ Percentage of dispersion Time (h) } \\
\cline { 2 - 4 } & 24 & 48 & 72 \\
\hline B $_{31}$ & 87 & 89 & 91 \\
Oil + antioxidant & 64 & 68 & 71 \\
Oil & 35 & 33 & 32 \\
\hline
\end{tabular}

Table 9 Percentage of sludge formation after and before addition of $2 \mathrm{wt} \%$ of the prepared additive and $0.5 \mathrm{wt} \%$ of antioxidant $\left(\mathrm{B}_{31}\right)$ at oxidation time $(72 \mathrm{~h})$

\begin{tabular}{ll}
\hline Sample & \% of sludge Time $(72 \mathrm{~h})$ \\
\hline $\mathrm{B}_{31}$ & 0.0932 \\
Oil + antioxidant & 0.2196 \\
Oil & 6.6776 \\
\hline
\end{tabular}

Table 9 which confirms that additive $\mathrm{B}_{31}$ has excellent power to remove sludge and deposit formed by oxidation than zinc dialkyldithiophosphate only.

\section{Conclusion}

The conclusions that could be derived from the results of this study are:

- Synthesis of propoxylated amines using different primary amines, then the products which were obtained react with different organic acids.

- The structures of the prepared compounds were confirmed by (FT-IR), (GPC), and (1H-NMR).

- All the prepared compounds are soluble in lubricating oil (SAE 30).

- The efficiency of the prepared compounds as lube oil additives (antioxidants and detergents/dispersants) was studied. It was found that all the prepared additives have excellent power of dispersion and detergency.

- It was found that the efficiency of the prepared compounds as antioxidants increases with increasing the number of $\mathrm{NH}$ group and by using of di-nbutyldithiophosphoric acid.

- It was found that the prepared additive $(B+D i-n-$ butyldithiophosphoric acid) " $\mathrm{B}_{3}$ " has synergistic effect with zinc dialkyldithiophosphate and increase its efficiency as antioxidants.

Open Access This article is distributed under the terms of the Creative Commons Attribution 4.0 International License (http:// creativecommons.org/licenses/by/4.0/), which permits unrestricted use, distribution, and reproduction in any medium, provided you give appropriate credit to the original author(s) and the source, provide a link to the Creative Commons license, and indicate if changes were made.

\section{References}

1. Gamal ANG, Mohamed SEG, Abd El-Moneim I, Hany A, Marwan, Ahmed A (2006) Upgrading of light dewaxed oil through hydrofinishing and additives blending for producing automatic transmission fluid. Am J Appl Sci 3(12):2136-2146

2. Guan L, Feng XL, Xiong G (2008) Engine lubricating oil classification by SAE grade and source based on dielectric spectroscopy data. Anal Chim Acta 628(1):117-120

3. Mao D, Van De Weghe H, Lookman R, Vanermen G, De Brucker N, Diels L (2009) Resolving the unresolved complex mixture in motor oils using high-performance liquid chromatography followed by comprehensive two-dimensional gas chromatography. Fuel 88(2):312-318

4. Alessandra B, Ronei JP (2005) Application of mid infrared spectroscopy and iPLS for the quantification of contaminants in lubricating oil. Vib Spectrosc 37(1):27-32

5. Kajdas D, Brown AJ, Jilbert D, Lamb G (2010) Industrial lubricants: chemistry and technology of lubricants, 3rd edn. London, New York, pp 239-292

6. Amal MN, Nehal SA, Khalid IA, Ahmed FE, Abdel-Azim AA (2006) Synthesis and evaluation of detergent/dispersant additives from polyisobutylene succinimdes. Int J Polym Mater 55(9): 703-713

7. Jian-Qiang H, Xian-Yong W, Ge-Lin D, Yi-Wei F, Chang-Cheng L, Zhi-Min Z, Jun-Bing Y (2007) Synergistic antioxidation of organic molybdenum complex with dithiocarbamate antioxidant evaluated by differential scanning calorimetry and thin film micro oxidation test. Thermochim Acta 453(1):21-26

8. Rizvi SQA (2009) Lubricant additives: a comprehensive review of lubricant chemistry, technology, selection, and design. ASTM International, West Conshohocken, 100-112,

9. Nehal SA and Amal MN (2013) lubrication and lubricants: tribology-fundamentals and advancements. Rijeka, Croatia, 55-76

10. Al-Sabagh AM, Azzam EM, Noor El-Din MR (2009) The surface and thermodynamic properties of ethoxylated sodium monoalkyl sulfosuccinate surfactants. J Dispersion Sci Technol 30(2): 260-266

11. Lamb GG, Loance CM, Gaynor JW (1941) Indiana stirring oxidation test for lubricating oils. Ind Eng Chem Anal Ed 13(5):317-321 
12. Gatis VA, Bergstrom RF and Wendt LA (1954) On the spot testing of used lubricating oils. Society of Automotive Engineers (SAE) paper, 572

13. Rubinshtein IA, Popova EA, Novosartov GT (1979) Method for determination of sludge formed during operation or storage of synthetic lube oils. Chem Technol Fuels Oils 15(3):223-225

14. Ádám B, Márk B and Jenő H (2011) Development of multifunctional detergent-dispersant additives based on fatty acid methyl ester for diesel and biodiesel fuel: biodiesel-quality, emissions and by-products, 153-170
15. Nehal SA, Amal MN, Rasha SK (2011) Influence of some compounds as antioxidants and detergents/dispersants for lube oil. J Dispersion Sci Technol 32(7):1067-1074

16. Al-Sabagh AM, Nasser NM, Mishrif MR, Abd-El-Raouf M (2013) Synthesis of some oil spill dispersants from locally alkyl benzene and evaluating their dispersion efficiency and toxicity. Dispersion Sci Technol 31:1752-1761 